\title{
The metabolic syndrome is not associated with homocysteinemia: The Persian Gulf Healthy Heart Study
}

\author{
I. Nabipour, A. Ebrahimi, S.M. Jafari, K. Vahdat, M. Assadi, A. Movahed, F. Moradhaseli, N. Obeidi, \\ and Z. Sanjdideh \\ Department of Endocrine and Metabolic Diseases, The Persian Gulf Tropical Medicine Research Center, Bushehr University of \\ Medical Sciences, Bushehr, I.R. Iran
}

\begin{abstract}
Background: It is uncertain whether homocysteine and the metabolic syndrome or its components are related in the general population, as studies investigating the association between homocysteine levels and insulin resistance have shown conflicting results. Methods: In an ancillary study to the Persian Gulf Healthy Heart Study, a cohort study of Iranian men and women aged $\geq 25 \mathrm{yr}$, a random sample of 1754 subjects were evaluated for the association of plasma homocysteine levels and the metabolic syndrome using National Cholesterol Education Program (NCEP)-Adult Treatment Panel (ATP)-III criteria. Total homocysteine levels and high sensitivity C-reactive protein (CRP) were determined by enzyme-linked immunosorbent assays. Results: Subjects with lower HDL-cholesterol and higher blood pressure showed significantly higher homocysteine levels $(p=0.001$ and $p<0.0001$; respectively). There was no significant differ-
\end{abstract}

\section{INTRODUCTION}

Elevated levels of serum total homocysteine are toxic to vascular endothelium, including endothelial dysfunction and contributing to development of atherosclerosis independent of standard cardiovascular disease (CVD) risk factors in diabetic and non-diabetic subjects (1).

Several observations suggest that there might be links between insulin resistance (IR) and hyperhomocysteinemia $(2,3)$. Hyperhomocysteinemia may be a cause and/or a consequence of IR. In an insulin resistant state, elevated homocysteine plasma levels may be the result of hyperinsulinemia, as observed in animal models $(4,5)$. At the same time, homocysteine may lead to IR through inhibition of insulin-receptor kinase activity in vitro $(6,7)$.

Plasma levels of insulin seem to influence homocysteine metabolism, possibly through effects on glomerular filtration or by influencing activity of key enzymes in homocysteine metabolism, including 5, 10-methylenetetrahydrofolate reductase or cystathione B-synthase (2). There is, however, conflicting evidence about whether there is a general relationship between IR and homocysteine levels in healthy humans (8-10).

The common clustering of glucose intolerance, abdominal adiposity, hypertriglyceridemia, low HDL-cholesterol (HDLC) level and high blood pressure in a single individual is re-

\footnotetext{
Key-words: C-reactive protein, homocysteine, insulin resistance, ischemic heart disease, metabolic syndrome.

Correspondence: I. Nabipour, MD, The Persian Gulf Tropical Medicine Research Center, Boostan 19 Alley, Imam Khomeini Street, Bushehr, I.R. Iran.

E-mail: inabipour@gmail.com - inabim@yahoo.com

Accepted October 28, 2008.
}

ence in serum levels of homocysteine between subjects with and without the metabolic syndrome. In multiple logistic regression analysis, the metabolic syndrome did not show a significant association with serum homocysteine levels after adjusting for sex, age, smoking, fruit and vegetable intake pattern, body mass index, and physical inactivity. Concurrent elevated CRP levels and the metabolic syndrome also did not show a significant association with serum homocysteine levels after adjusting for sex, age, and lifestyle cardiovascular risk factors. Conclusions: There was no association between the metabolic syndrome using NCEP-ATPIII criteria and homocysteinemia in this study. These data refute the hypothesis that homocysteine levels are influenced by the metabolic syndrome, at least in general healthy population.

(J. Endocrinol. Invest. 32: 406-410, 2009)

๑2009, Editrice Kurtis

ferred to as the metabolic syndrome $(11,12)$. The metabolic syndrome is expected to be diagnosed in millions of subjects in the near future worldwide by both World Health Organization (WHO) and National Cholesterol Education Program (NCEP)-Adult Treatment Panel (ATP)-III (NCEPATP III) criteria. The prevalence of metabolic syndrome has been reported to be $24 \%$ in the US adult population (12). IR is considered to be the major underlying pathophysiological feature of the metabolic syndrome, as it interferes in many metabolic pathways (13).

Although hyperhomocysteinemia and the metabolic syndrome are both associated with CVD, the association between fasting homocysteine levels and metabolic syndrome is not well characterized and studies investigating the association between the metabolic syndrome and homocysteine levels have shown conflicting results $(2,3,14-16)$. A very few population-based studies reported the association of metabolic syndrome and hyperhomocysteinemia (14-16). Of these, one in Mexican American men failed to show an association between homocysteinemia and diabetes status or fasting serum insulin (15), whereas the other, from the Framingham Offspring Study, did show a moderate association between components of the metabolic syndrome and homocysteine levels (2). There is limited data about the relationship between hyperhomocysteinemia and the metabolic syndrome in Asian countries (16). The main objective of this study is to investigate the association of metabolic disease and its major components with homocysteine using NCEP-ATP III criteria.

\section{MATERIALS AND METHODS}

The Persian Gulf Healthy Heart Study is set up to determine the 
risk factors for CVD among the Northern Persian Gulf population (Bushehr and Hormozghan Provinces) and to develop community-based interventional projects to change the lifestyles of the population. The design of this study encompasses two major components: phase I is a cross-sectional prevalence study of unhealthy lifestyle and ischemic heart disease (IHD) and associated risk factors, and phase II is a multiple interventional project for reduction of CVD in the region.

\section{Community sampling and baseline examinations}

In phase I of the study, a multiple-stage stratified cluster random sampling technique was used to select 3000 people aged $\geq 25 \mathrm{yr}$ from major ports of Bushehr Province (an Iranian province with the greatest border with the Persian Gulf). The studied ports of the Northern Persian Gulf were Bushehr Port (the center of Bushehr Province, with a population of 150,000 and coronary events of 481.05 and 156.61 per 100,000 for men and women, respectively), Genaveh and Deilam Ports. Examinations were conducted in 2003-04. All subjects were asked to fast and to arrive at the survey center between 7:30-9:30 h. Blood pressure was assessed twice on the right arm after a 15-min rest in the sitting position, using a standard mercury sphygmomanometer. Height and weight were measured using a stadiometer. Heavy outer garments and shoes were removed before measuring height and weight. Body mass index (BMI) was calculated. Waist circumference was defined at the midway level between the costal margins and the iliac crests. Hip circumference was measured at the level of the greater trochanters. A resting 12-lead electrocardiogram was performed. A fasting blood sample was taken, all samples were promptly centrifuged, separated and analyses were carried out at the Persian Gulf Health Research Center on the day of blood collection using a Selectra 2 autoanalyzer (Vital Scientific, Spankeren, The Netherlands). Glucose was assayed by enzymatic (glucose oxidase) colorimetric method using a commercial kit (Pars Azmun Inc; Tehran, Iran). Serum total cholesterol and HDL-C were measured using a cholesterol oxidase phenol aminoantipyrine and triglycerides using a glycerol-3 phosphate oxidase phenol aminoantipyrine enzymatic method. Serum LDL-cholesterol was calculated using the Friedwald formula; LDL-cholesterol was not calculated when triglyceride concentration was $>400 \mathrm{mg} / \mathrm{dl}$.

The metabolic syndrome was diagnosed with the criteria indicated by the NCEP-ATP III (17). According to these criteria, subjects with the metabolic syndrome are those with any combination of three or more of the following risk determinants: fasting plasma glucose $\geq 6.1 \mathrm{mmol} / \mathrm{l}$, blood pressure $\geq 130 / \geq 85$ $\mathrm{mmHg}$ or antihypertensive treatment, plasma triglycerides $\geq 1.7 \mathrm{mmol} / \mathrm{l}$, plasma HDL-C $<1.03 \mathrm{mmol} / \mathrm{l}$ in men and $<1.29$ $\mathrm{mmol} / \mathrm{l}$ in women, and waist circumference $>102 \mathrm{~cm}$ in men or $>88 \mathrm{~cm}$ in women.

EKGs were coded on the basis of the Minnesota coding criteria (18). Codes 1.1, 1.2, 1.3, 4.1-4.4, 5.1-5.3, and 7.1 were classified as electrocardiographic-defined coronary artery disease (CAD).

\section{Serology}

Sera were screened for lgG antibodies against Helicobacter pylori with an enzyme-linked immunosorbent assay (ELISA) (RADIM SpA, Italia), and the samples were considered positive with IgG values higher than $30 \mathrm{RU} / \mathrm{ml}$. An enzyme immunoassay for the determination of total homocysteine in blood was used; the quantification limit of the DRG Homocysteine EIA (DRG International, Inc. USA) was $1.0 \mu \mathrm{mol} / / \mathrm{l}$ with a coefficient of variation (CV) $<20 \%$. Sera were separated shortly after collection, to avoid artifactual in- creases. The interference with the DRG Homocysteine was $<10 \%$ for bilirubin, hemoglobin, lipids, protein and red blood cells. Measurement of CRP by a high-sensitivity CRP (hs-CRP) assay was carried out. The minimum detectable concentration of the CRP HS ELISA (DRG International, Inc. USA) assay was estimated to be 0.1 $\mathrm{mg} / \mathrm{l}$. Additionally, the functional sensitivity was determined to be $0.1 \mathrm{mg} / \mathrm{l}$ (as determined with inter-assay \% CV <20\%).

\section{Statistical methods}

The significance of the difference in the results of the two groups was determined by chi-square analysis using $2 \times 2$ contingency tables. A two-tailed t-test was used to compare the mean values across groups. $p<0.05$ was considered statistically significant. We found that log transformation of CRP gave a better fit to a Gaussian distribution. The geometric mean for CRP was defined as the arithmetic mean of the log-transformed data $\pm 2 \mathrm{SD}$, raised to the power of 10 .

Multiple logistic regression analysis was used to ascertain the associations between the metabolic syndrome and homocysteinemia. Sex, age, smoking, fruit, and vegetable intake pattern, $\mathrm{BMI}$ and physical inactivity were considered as covariates, and the metabolic syndrome also as the dependent variable. $p<0.05$ was considered statistically significant. Statistical analysis was performed with an IBM computer using the SPSS 9.05 statistical software package (SPSS Inc., Chicago, IL).

\section{RESULTS}

A total of 1754 (49.2\% males, $50.8 \%$ females) of the studied population were evaluated for associations of the metabolic syndrome and serum levels of homocysteine. Of the studied subjects, $36.1 \%$ was between $25-34 \mathrm{yr}$, $29.0 \%$ between $35-44 \mathrm{yr}$, $21.9 \%$ between $45-54 \mathrm{yr}$, and $12.7 \%$ between $55-66 \mathrm{yr}$.

The prevalence of consumption of antihypertensive, hypolipidemic and anti-diabetic drugs were $6.5 \%, 3.5 \%$ and $3.8 \%$, respectively.

A total of $52.1 \%$ of the subjects $(56.30 \%$ of males and $48.0 \%$ of females; $p<0.0001$ ) had the metabolic syndrome (NCEP-ATP III criteria).

Clinical characteristics, laboratory values and homocysteine levels in males and females are presented in Table 1. The mean of homocysteine was $14.71(7.09) \mu \mathrm{mol} / \mathrm{l}$ in the studied population. Quartiles $(\mathrm{Q})$ for the population distribution for homocysteine were as follows: Q1, 0.1-10.2 $\mu \mathrm{mol} / \mathrm{l} ; \mathrm{Q} 2,10.3-14.30 \mu \mathrm{mol} / \mathrm{l} ; \mathrm{Q} 3,14.31-18.80 \mu \mathrm{mol} / \mathrm{l}$; and $\mathrm{Q} 4,18.81-46.70 \mu \mathrm{mol} / \mathrm{l}$. The mean levels of homocysteine were higher in men $(16.85, \mathrm{SD}=7.33 \mu \mathrm{mol} / \mathrm{l})$ than women (12.67, SD=6.19 $\mu \mathrm{mol} / \mathrm{l}),(p<0.0001)$.

There was no significant difference in serum levels of homocysteine between subjects with and without the metabolic syndrome [17.09 (6.85 SD) vs 16.55 (7.89) $\mu \mathrm{mol} / \mathrm{l}$ for men and 12.91 (6.25) vs 12.45 (6.14) $\mu \mathrm{mol} / \mathrm{l}$ for women, respectively $(p>0.05)]$.

Mean homocysteine levels did not differ significantly in subjects with and without impaired fasting glucose [15.26 (8.64) $\mu \mathrm{mol} / \mathrm{l}$ and $14.81(6.99) \mu \mathrm{mol} / \mathrm{l}$, respectively $(p>0.05)]$. Mean homocysteine levels were compared between two groups divided by each component of metabolic syndrome (Table 2). Subjects with lower HDL-C and higher blood pressure showed significantly higher homocysteine levels ( $p=0.001$ and $p<0.0001$; respectively). 
Table 1 - Clinical characteristics and laboratory values of a random population of the northern Persian Gulf (the study population).

\begin{tabular}{|c|c|c|c|}
\hline & $\begin{array}{c}\text { Men } \\
\text { (no.=864) }\end{array}$ & $\begin{array}{c}\text { Women } \\
\text { (no.=890) }\end{array}$ & $p$ \\
\hline$\overline{\text { Waist }(\mathrm{cm})}$ & $94.4(11.5)$ & $98.2(14.1)$ & $<0.0001$ \\
\hline BMI $\left(\mathrm{kg} / \mathrm{m}^{2}\right)$ & $26.0(4.6)$ & $28.3(5.6)$ & $<0.0001$ \\
\hline Systolic blood pressure $(\mathrm{mmHg})$ & $130.9(47.4)$ & $121.4(23.5)$ & $<0.0001$ \\
\hline Diastolic blood pressure $(\mathrm{mmHg})$ & $83.7(47.5)$ & $77.2(189.2)$ & $<0.0001$ \\
\hline Total Cholesterol (mg/dl) & $201.6(46.4)$ & $210.2(48.7)$ & $<0.0001$ \\
\hline HDL-cholesterol (mg/dl) & $41.4(31.3)$ & $48.0(42.2)$ & $<0.0001$ \\
\hline LDL-cholesterol (mg/dl) & $123.9(49.5)$ & $130.0(58.0)$ & 0.01 \\
\hline Triglyceride (mg/dl) & $181.0(108.8)$ & $160.8(95.2)$ & $<0.0001$ \\
\hline Fasting blood sugar (mg/dl) & $91.2(36.0)$ & $93.2(44.1)$ & ns \\
\hline C-reactive protein $(\mathrm{mg} / \mathrm{l})^{\star}$ & $1.62(3.16)$ & $3.98(4.07)$ & $<0.0001$ \\
\hline Homocysteine $(\mu \mathrm{mol} / \mathrm{l})$ & $16.85(7.33)$ & $12.67(6.19)$ & $<0.0001$ \\
\hline Ischemic heart disease (\%) & 8.0 & 14.6 & $<0.0001$ \\
\hline Myocardial infarction (\%) & 1.6 & 1.0 & ns \\
\hline Metabolic syndrome (\%) & 56.3 & 48.0 & $<0.0001$ \\
\hline Low fruit and vegetable intake (\%) & 92.2 & 90.4 & ns \\
\hline Physical inactivity (\%) & 68.5 & 73.1 & 0.01 \\
\hline Smoking (\%) & 36.5 & 21.9 & $<0.0001$ \\
\hline
\end{tabular}

Values are mean (SD), except for smoking, physical inactivity, metabolic syndrome, ischemic heart disease, myocardial infarction, low fruit and vegetable intake. BMI: body mass index; *Geometric mean (SD).

Table 3 shows age-adjusted odds ratios (OR) [95\% confidence interval $(\mathrm{Cl})]$ between metabolic syndrome, and lifestyle cardiovascular risk factors, and serum homocysteine levels. In multiple logistic regression analysis, the metabolic syndrome did not show a significant association with serum homocysteine levels in males [OR=1.00, $\mathrm{Cl}(0.98-1.02) ; p=0.47]$ and females [OR=1.00, $\mathrm{Cl}(0.97-$ $1.02) ; p=0.84]$ after adjusting for age, smoking, fruit and vegetable intake pattern, $\mathrm{BMI}$, and physical inactivity.

Concurrent elevated CRP levels (defined as more than $3.0 \mathrm{mg} / \mathrm{l}$ ) and the metabolic syndrome (concurrent elevated CRP and the metabolic syndrome) also did not show a significant association with serum homocysteine

Table 2 - The differences in homocysteine values according to the presence or absence of metabolic syndrome components in a random population of the northern Persian Gulf.

\begin{tabular}{|c|c|c|c|}
\hline & no. $=1754$ & $\begin{array}{l}\text { Homocysteine } \\
(\mu \mathrm{mol} / \mathrm{l})\end{array}$ & $p$ \\
\hline $\begin{array}{l}\text { Waist circumference }(\mathrm{cm}) \\
\geq 102 \text { for men } / \geq 88 \text { for women } \\
<102 \text { for men } /<88 \text { for women }\end{array}$ & $\begin{array}{c}1479 \\
181\end{array}$ & $\begin{array}{l}14.62 \pm 7.06 \\
15.51 \pm 7.31\end{array}$ & 0.128 \\
\hline $\begin{array}{l}\text { Triglyceride (mg/dl) } \\
\geq 150 \\
<150\end{array}$ & $\begin{array}{l}808 \\
852\end{array}$ & $\begin{array}{l}15.05 \pm 6.93 \\
14.40 \pm 0.22\end{array}$ & 0.060 \\
\hline $\begin{array}{l}\text { HDL-cholesterol }(\mathrm{mg} / \mathrm{dl}) \\
<40 \text { for } \mathrm{men} /<50 \text { for women } \\
\geq 40 \text { for men } / \geq 50 \text { for women }\end{array}$ & $\begin{array}{c}1048 \\
612\end{array}$ & $\begin{array}{l}15.18 \pm 6.97 \\
13.92 \pm 7.21\end{array}$ & 0.001 \\
\hline $\begin{array}{l}\text { Blood pressure }(\mathrm{mmHg}) \\
\geq 130 / 85 \\
<130 / 85\end{array}$ & $\begin{array}{l}664 \\
996\end{array}$ & $\begin{array}{l}15.62 \pm 7.08 \\
14.11 \pm 7.03\end{array}$ & $<0.0001$ \\
\hline $\begin{array}{l}\text { Fasting glucose }(\mathrm{mg} / \mathrm{dl}) \\
\geq 110 \\
<110\end{array}$ & $\begin{array}{c}183 \\
1477\end{array}$ & $\begin{array}{l}13.85 \pm 7.82 \\
14.82 \pm 6.99\end{array}$ & 0.079 \\
\hline
\end{tabular}

levels in males [OR=1.01, $\mathrm{Cl}(0.98-1.04) ; p=0.39]$ and females [OR=0.99 $\mathrm{Cl}(0.96-1.02) ; p=0.70]$ adjusting for age and lifestyle cardiovascular risk factors.

The metabolic syndrome, in subjects with non-fatal IHD by electrocardiogram criteria was not associated with elevated levels of homocysteine compared to subjects without concurrent metabolic syndrome and non-fatal IHD [14.74 (7.12) $\mu \mathrm{mol} / \mathrm{l} v \mathrm{vs} 14.40$ (6.66) $\mu \mathrm{mol} / \mathrm{l}$, respectively].

\section{DISCUSSION}

In this study, there was no association between the metabolic syndrome using NCEP-ATP III criteria and homocysteinemia. Homocysteine values according to the presence or absence of abdominal obesity, hypertriglyceridemia, hypertension, and fasting hyperglycemia showed no significant differences. On the other hand, serum homocysteine levels were significantly higher in subjects with low HDL-C and higher blood pressure, two metabolic syndrome criteria.

The studies on the relationship between homocysteine levels and metabolic syndrome or IR show conflicting results $(2,3,14-16)$. Most studies have been based on small population samples or have been restricted to diabetic patients. To our knowledge, only 5 other large-scale epidemiological studies exist to date $(2,3,14-16)$. Of these, 3 studies have investigated the relationships between homocysteinemia, serum insulin, and features of IR syndrome $(2,3,15)$. Meigs et al. assessed the relationship between hyperinsulinemia, phenotypes of IR syndrome, and levels of fasting homocysteine in the population-based Framingham Offspring Study (2). They found positive associations between fasting levels of plasma homocysteine and some individual traits associated with IR (2).

In contrast, in a national sample of Mexican American men aged 40-74 yr, serum homocysteine was not associated with prevalent diabetes mellitus, body fat distribution, obesity or other variables of the IR syndrome (15). In a recent work by Bjorck et al., a significant association between homocysteine and both serum insulin and homeostasis model assessment (HOMA) of IR were found in a population-based sample of Swedish men and women (3). These studies investigated the relationship between homocysteine levels and IR, thus linking homocysteine and the metabolic syndrome indirectly. However, NCEP-ATP III criteria for definition of metabolic syndrome were only used in two large recent studies (14-16). In 722 participants undergoing medical checkups in a university hospital in Korea, homocysteine levels failed to show statistically significant association with metabolic syndrome defined by either the modified NCEP-ATP III or newly recommended International Diabetes Federation criteria (16). Garcin et al. used NCEP-ATP III criteria of the metabolic syndrome in a French male population (14). Mean homocysteinemia was 10.96 (5.01) $\mu \mathrm{mol} / \mathrm{l}$ for the whole population and did not differ significantly with [11.4 (6.0) $\mu \mathrm{mol} / \mathrm{l}]$ or without [10.9 (5.0) $\mu \mathrm{mol} / \mathrm{l}]$ the metabolic syndrome, as dose value distribution. Plasma homocysteine level did not correlate with the metabolic syndrome criteria (14).

The present study indicates that homocysteine levels were independent of the metabolic syndrome using NCEP-ATP 
Table 3 - Age-adjusted odds ratios (OR) and 95\% confidence intervals (CI) relating the metabolic syndrome as dependent variable, homocysteinemia and associated risk factors as independent parameters in the Northern Persian Gulf adults.

\begin{tabular}{|c|c|c|c|c|c|c|}
\hline & \multicolumn{3}{|c|}{ Men } & \multicolumn{3}{|c|}{ Women } \\
\hline & OR & $95 \% \mathrm{Cl}$ & $p$ & OR & $95 \% \mathrm{Cl}$ & $p$ \\
\hline Homocysteine & 1.00 & $0.98-1.02$ & 0.47 & 1.00 & $0.97-1.02$ & 0.84 \\
\hline Smoking & 1.39 & $0.99-1.95$ & 0.05 & 1.42 & $0.98-2.06$ & 0.06 \\
\hline Physical inactivity & 0.63 & $0.45-0.88$ & 0.08 & 1.16 & $0.83-1.61$ & 0.37 \\
\hline Low fruit and vegetable intake & 1.27 & $0.70-2.31$ & 0.41 & 0.84 & $0.50-1.39$ & 0.49 \\
\hline Body Mass Index & 1.23 & $1.17-1.28$ & $<0.0001$ & 1.11 & $1.07-1.14$ & $<0.0001$ \\
\hline
\end{tabular}

III criteria. This is in accordance with the findings of those studies (the Korean and French studies) that used the same criteria for the metabolic syndrome $(14,16)$.

The strength of our study is its community-based epidemiological setting. Participants of the Korean study were from the medical checkup program (16). The population sample of this study is the largest one in the Asian countries and comprises males and females from a general population, while the French study was on a male population only (14). Among the various diagnostic criteria published up to date, the NCEP-ATP III definition is overwhelmingly the most common definition used in research studies, although numerous limitations have been proposed in multiple studies (16). Current general conceptual frameworks include 1) viewing the metabolic syndrome epidemic as being attributable to environmental causes (e.g., the basic approach of NCEP ATP III), 2) viewing the syndrome as primarily the result of IR (e.g., the WHO approach), and 3) viewing inflammation as the underlying cause of the syndrome (19). Given the consistency of prognostic data for hsCRP and the practicality of its use in outpatient clinical settings, some believe the time has come for a careful consideration of adding hsCRP as a clinical criterion for metabolic syndrome and for creation of an hsCRP-modified coronary risk score useful for global risk prediction in both men and women (20). However, by adding elevated hsCRP levels to the definition of metabolic syndrome (concurrent elevated CRP and the metabolic syndrome), we did not find a difference in homocysteine levels between subjects with concurrent elevated CRP and the metabolic syndrome and without elevated hsCRP levels.

In the French study (14), plasma homocysteine level did not correlate with the metabolic syndrome main criteria but, in the Korean study (16), subjects with larger waist circumference and higher fasting blood glucose levels showed significantly higher homocysteine levels. We found that subjects with low HDL-C, as a main criterion of the metabolic syndrome, had higher levels of homocysteine. It has been reported that homocysteine is inversely correlated with plasma HDL-C and apolipoprotein (Apo) A-l in patients with coronary heart disease (21). Liao et al. confirmed this negative correlation in mice with targeted deletions of the genes for apoE and cystathionine beta-synthase (CBS) (22). Severe (plasma homocysteine $210 \mu \mathrm{mol} / \mathrm{l})$ accelerates spontaneous arthrosclerosis in the CBS(-/-)/apoE(-/-) mice, reduces the concentration of circulating HDL, apoA-I, and large HDL particles, inhibits HDL function, and enhances HDL-C clearance. Findings indicate that hyperhomocysteinemia inhibits reverse cholesterol transport by reducing circulating $\mathrm{HDL}$ via inhibiting apoA-I protein synthesis and enhancing HDL-C clearance. These studies suggest that homocysteine-induced HDL-C and apoA-I inhibition represents a novel mechanism by which homocysteine induces atherosclerotic CVD (22).

Lack of information on vitamin status is one limitation in the previous studies which assessed a link with homocysteine and the metabolic syndrome. A high intake of folate and vitamin $B_{6}$ and $B_{12}$ is known to correlate with low homocysteine levels (23). Meat, fish and dairy products are all good sources of methionine, and vegetables containing folic acid, beta-carotene, and vitamin C effectively lowered homocysteine levels (16). We used a 6item food frequency questionnaire of Behavioral Risk Factor Surveillance System (BRFSS), Centre for Desease Control USA (CDC/USA) (24) to assess the recommendation of consuming fruits and vegetables 5 or more times per day in the present study. A previous research has shown that the magnitude of the correspondence between BRFSS estimates and reference methods of dietary intake does not vary consistently by age, gender, or education (25). We adjusted fruit and vegetable consumption in logistic regression model to assess the association of the metabolic syndrome and homocysteine levels.

We acknowledge study limitations. In the present study we used NCEP-ATP III definition for the metabolic syndrome. Although this definition is most often used, other definitions for the metabolic syndrome do exist. Another limitation of our study includes the lack of measurement of IR from fasting glucose and insulin concentrations using the HOMA method. Future research should include longitudinal studies of IR syndrome and serum homocysteine, and vitamin levels to determine temporal sequence of any relationship. Euglycemic clamp, minimal model or other techniques for accurate measurement of IR and specific insulin assays should be used to confirm whether IR, fasting specific insulin and proinsulin vary in their association with serum homocysteine.

In conclusion, the present study failed to show any significant association between homocysteine levels and metabolic syndrome defined by NCEP-ATP III criteria in a general Iranian population. These data refute the hypothesis that homocysteine levels are influenced by the metabolic syndrome, at least in general healthy population.

Whereas the cross-sectional nature of our analysis precludes assigning cause or effect to the metabolic syndrome or hyperhomocysteinemia, the phase II of the Persian Gulf Healthy Heart Study is ongoing in an Iranian population with a high prevalence of the metabolic syndrome, predicting Type 2 diabetes and cardiovascular 
events. The result of this large prospective study will better clarify any cause-effect relation of hyperhomocysteinemia with the metabolic syndrome.

\section{ACKNOWLEDGMENTS}

This study was supported in part by a grant from Joint Ministry of Health and World Health Organization Regional Office (JPRM) fund (A/C: 02.01.01.01.ACS 2002-03), Bushehr Province Technology and Research Committee and Research Deputy of Bushehr University of Medical Science. We wish to thank Dr. Seyed Reza Imami and Dr. Abbass Nosrati for their kind assistance in field survey.

\section{REFERENCES}

1. Eikelboom JW, Lonn E, Genest J, Hankey G, Yusuf S. Homocysteine and cardiovascular disease: a critical review of the epidemiologic evidence. Ann Intern Med 1999, 131: 363-75.

2. Meigs JB, Jacques PF, Selhub J, et al. Fasting plasma homocysteine levels in the insulin resistance syndrome. The Framingham Offspring Study. Diabetes Care 2001, 24: 1403-10.

3. Bjorck J, Hellgren M, Rastam L, Lindblad ULF. Associations between serum insulin and homocysteine in a Swedish population- a potential link between the metabolic syndrome and hyperhomocysteinemia: The Skaraborg project. Metabolism 2006, 55: 1007-13.

4. Fonseca V, Dicker-Brown A, Ranganathan S, et al. Effects of a highfat-sucrose diet on enzymes in homocysteine metabolism in the rat. Metabolism 2000, 49: 736-41.

5. Oron-Herman M, Rosenthal T, Sela BA. Hyperhomocysteinemia as a component of syndrome X. Metabolism 2003, 52: 1491-5.

6. Najib S, Sanchez-Margalet V. Homocysteine thiolactone inhibits insulin signaling, and glutathione has a protective effect. J Mo Endocrinol 2001, 27: 85-91.

7. Najib S, Sanchez-Margalet V. Homocysteine thiolactone inhibits insulin-stimulated DNA and protein synthesis: possible role of mitogen-activated protein kinase (MAPK), glycogen synthase kinase3 (GSK-3) and p70 S6K phosphorylation. J Mol Endocrinol 2005 34: 119-26.

8. Tanrikulu-Kilic F, Bekpinar S, Unlucerci Y, Orhan Y. Insulin resistance is not related to plasma homocysteine concentration in healthy premenopausal women. Physiol Res 2006, 55: 285-90.

9. Godsland IF, Rosankiewicz JR, Proudler AJ, Johnston DG. Plasma total homocysteine concentrations are unrelated to insulin sensitivity and components of the metabolic syndrome in healthy men. J Clin Endocrinol Metab 2001, 86: 719-23.

10. Giltay EJ, Hoogveen EK, Elbers JMH, Gooren LJG, Asscheman H Stehouwer CDA. Insulin resistance is associated with elevated plasma total homocysteine levels in healthy non-obese subjects. Atherosclerosis 1998, 139: 197-8.
11. Liese AD, Mayer-Davis EJ, Haffner SM. Development of the multiple metabolic syndromes: an epidemiologic perspective. Epidemiol Rev 1998, 20: 157-72.

12. Ford ES, Giles WH, Mokdad AH. Increasing prevalence of the metabolic syndrome among U.S. adults. Diabetes Care 2004, 27 2444-9.

13. Liao Y, Kwon S, Shaughnessy S, et al. Critical evaluation of adult treatment panel III criteria in identifying insulin resistance with dyslipidemia. Diabetes Care 2004, 27: 978-83.

14. Garcin JM, Cremades S, Garcia-Hejl C, et al. Is hyperhomocysteinemia an additional risk factor of the metabolic syndrome? Metab Syndr Relat Disord 2006, 4: 185-95.

15. Gillum R. Distribution of serum total homocysteine and its association with diabetes and cardiovascular risk factors of the insulin re sistance syndrome in Mexican American Men: The Third National Health and Nutrition Examination Survey. Nutrition J 2003, 2: 6.

16. Rhee EJ, Hwang ST, Lee WY, et al. Relationship between metabolic syndrome categorized by newly recommended by international diabetes federation criteria with plasma homocysteine concentration. Endocrine J 2007, 54: 995-1002.

17. Expert Panel on Detection, Evaluation and Treatment of High Blood Cholesterol in Adults: Executive summary of the Third Report of the National Cholesterol Education Program (NCEP) Expert Panel on Detection, Evaluation and Treatment of High Blood Cholesterol in Adults (Adult Treatment Panel III). JAMA 2001, 285: 2486-97.

18. Prineas RJ, Crowe RS, Blackburn H. The Minnesota Code manual of electrocardiographic findings. Bristol: John Wright, 1982.

19. Haffner SM. The metabolic syndrome: inflammation, diabetes mellitus, and cardiovascular disease. Am J Cardiol 2006, 97 (Suppl): 3A-11A

20. Ridker PM, Wilson WF, Grundy SM. Should C-reactive protein be added to metabolic syndrome and to assessment of global cardiovascular risk? Circulation 2004, 109: 2818-25.

21. Liao D, Yang $X$, Wang $H$. Hyperhomocysteinemia and high-density lipoprotein metabolism in cardiovascular disease. Clin Chem Lab Med 2007, 45: 1652-9.

22. Liao D, Tan H, Hui $R$, et al. Hyperhomocysteinemia decreases circulating high-density lipoprotein by inhibiting apolipoprotein A-I protein synthesis and enhancing HDL cholesterol clearance. Cir Res 2006, 99: 565-6.

23. Jacques PF, Bostom AG, Wilson PW, Rich S, Rosenberg IH, Selhub J. Determination of plasma total homocysteine concentration in the Framingham Offspring cohort. Am J Clin Nutr 2001, 73: 613-21.

24. Battelle Memorial Institute. Evaluation of the behavioral risk factor surveillance system (BRFSS) as a source of national estimates for selected health risk behaviors: Final Report. Baltimore, Md: Battelle Memorial Institute, 1999.

25. Serdula M, Coates R, Byers $T$, et al. Evaluation of a brief telephone questionnaire to estimate fruit and vegetable consumption in diverse study populations. Epidemiology 1993, 4: 455-63. 